\title{
INVESTMENT, IRREVERSIBILITY, AND UNCERTAINTY IN ENERGY BEET-BASED ETHANOL
}

\author{
KASSU WAMISHO HOSSISO* \\ Burean of Economic Analysis, the U.S. Department of Commerce, Suitland, Maryland \\ DAVID RIPPLINGER \\ Department of Agribusiness and Applied Economics, North Dakota State University, Fargo, North Dakota
}

\begin{abstract}
This study evaluates optimal investment decision rules for an energy beet ethanol firm to exercise the option to invest, mothball, reactivate, and exit the ethanol market, considering uncertainty and volatility in the market price of ethanol, feedstock, and irreversible investment. A real options framework is used to compute gross margins of ethanol that trigger entry into and exit from the ethanol market. Results show that volatility in ethanol gross margins has much greater effects on exit and entry decisions than investment costs, and it also causes firms to wait longer before entering the ethanol market and, once active, to wait longer before exiting.
\end{abstract}

Keywords: Energy beets, ethanol, investment, irreversibility, real options, uncertainty

JEL Classifications: Q20, Q42, L13

\section{Introduction}

Spurred by the Energy Independence and Security Act of 2007, the U.S. biofuel industry has experienced significant growth. So far, this growth in biofuel production has primarily occurred through corn-based ethanol. Currently, the corn ethanol industry has reached the annual minimum production capacity required to meet the "conventional" renewable fuel standard (RFS2) mandate (Renewable Fuel Association, 2015). This suggests that future growth in biofuel production may be met by alternative "advanced" feedstocks, including agricultural waste, biomass, and high sugar crops such as sugar beets, sugarcane, and sweet sorghum.

The authors would like to thank Edie Nelson and Aaron DeLaporte for their editorial assistance, and three anonymous reviewers for their insightful comments on a previous version of this paper. This paper was prepared by Kassu Wamisho Hossiso (in collaboration with David Ripplinger) in his personal capacity. The opinions expressed in this paper are the author's own and do not reflect the views of the Bureau of Economic Analysis, the U.S. Department of Commerce, or the United States government.

*Corresponding author e-mail: kassu.hossiso@bea.gov 
Sugar feedstocks are potential candidates among a number of feedstock pathways that are able to meet the RFS2 advanced biofuel mandates (Coyle, 2010; Linton et al., 2011; Outlaw et al., 2007; Shapouri, Salassi, and Fairbanks, 2006). Nonetheless, there are currently no commercial-scale sugar-based ethanol refineries in operation or construction in the United States. However, efforts are underway to develop energy beet ethanol refineries in North Dakota and California. The energy beet, a member of the beet family (Beta vulgaris), is a hybrid sugar beet that has been genetically engineered in various parts of the United States to yield sugar for ethanol production (McGrath and Townsend, 2015; Wamisho, Ripplinger, and De Laporte, 2015). Although energy beets are specific to the United States, sugar beets are used in Europe for ethanol and sugar production.

The decision to invest in a new beet ethanol refinery is a dynamic process that is affected largely by ethanol price volatility, feedstock price, irreversible investments, and government policies. Because beet ethanol refinery investments have large sunk costs and the biorefinery is likely to operate in an uncertain market environment, potential investors have the option to delay investment decisions until additional price, cost, and policy information arises. The objective of this study is to assess the value of the opportunity to invest in a beet ethanol biorefinery and determine how the optimal decision rules for entry, mothballing, reactivation, and abandoning are affected by the volatilities of ethanol and beet prices and sunk costs. A real options value approach is used to estimate the ethanol gross margins that potentially trigger entry into and exit from the market.

Studies have evaluated the economic feasibility of ethanol investments in sugar-based feedstocks such as sweet sorghum, sugarcane, and sugar beets in the United States (Coyle, 2010; Linton et al., 2011; Maung and Gustafson, 2011; Outlaw et al., 2007; Rahmani and Hodges, 2006; Shapouri, Salassi, and Fairbanks, 2006; Wamisho, Ripplinger, and De Laporte, 2015). However, all of these studies have used discounted cash flow techniques such as net present value (NPV) or break-even value analysis, methods that do not adequately account for managerial flexibility and the risk and uncertainty of future cash flows. The option valuation approach has become a preferred technique because it models decision makers' flexible options to abandon, defer, or expand a project using new information (Dixit, 1989; Dixit and Pindyck, 1994).

The application of real options techniques to evaluate investment decisions in the U.S. ethanol industry has been limited in the past. However, notable applications of the real options approach (ROA) have evaluated investments in the U.S. biofuel industry (Cai and Stiegert, 2014; Gallagher, Shapouri, and Brubaker, 2007; Gonzalez, Karali, and Wetzstein, 2012; Paulson et al., 2008; Pederson and Zou, 2009; Schmit, Luo, and Conrad, 2011; Schmit, Luo, and Tauer, 2009). Recently, a growing body of literature has analyzed key factors affecting ethanol investment decisions including government subsidy policies, economic factors, and strategic interactions in the ethanol industry sector in the 
United States, Canada, and Europe (Lade, Lin Lawell, and Smith, 2016; Lin and Yi, 2015; Schmit, Luo, and Conrad, 2011; Thome and Lin Lawell, 2015; Yi and Lin Lawell, 2016; Yi, Lin, and Thome, 2015). In terms of evaluating the effects of government policy on entry and exit decisions of corn ethanol plants, Schmit, Luo, and Conrad (2011) implemented ROA to evaluate how RFS policies affect the investment behavior of U.S. corn ethanol firms and decisions of industry entry and exit in the U.S. ethanol market. Yi, Lin, and Thome (2015) analyzed the effect of government subsidies including volumetric production, investment, and entry subsidies in U.S. fuel ethanol industry. Furthermore, Lade, Lin Lawell, and Smith (2016) developed a dynamic model of compliance based on a final enforcement ruling of RFS2 by the Environmental Protection Agency (EPA) and demonstrated how uncertainty about future relative fuel prices and changes in policy expectations can have dramatic effects on the price of compliance credits and ethanol production in the U.S. ethanol industry. For example, Lade, Lin Lawell, and Smith (2016, p. 28) found that the EPA's policy created uncertainty following the release of the 2014 Final Rule: "event day loss estimates range between $\$ 120$ and $\$ 215$ million, and increase over a twoand five-day horizon." In addition, Thome and Lin Lawell (2015), Lin and Yi (2015), and Yi and Lin Lawell (2016) built a reduced form of discrete response and a structural econometric model of a dynamic game to analyze how economic factors, government policy, and strategic interactions affect timing and place of decisions to invest in ethanol plants in the United States, Canada, and Europe.

Studies outside the biofuel industry have addressed the following: the option to temporarily shut down (Brennan and Schwartz, 1985; McDonald and Siegel, 1985); the option to continue or discontinue a planned investment (Majd and Pindyck, 1987) and deferred investment (McDonald and Siegel, 1985); the value of flexibility in alternative investment decisions, multistage projects, and switching options (Kulatilaka, 1986; Trigeorgis, 1996); and shutdown and upgrade decisions of wind turbine owners in Denmark based on a dynamic structural econometric model (Cook and Lin Lawell, 2015).

The application of the ROA to beet ethanol investment analysis in this article makes several important contributions to the literature. First, the real options framework is applied to energy beet investors, allowing managerial flexibility to demonstrate how the uncertainty of ethanol and beet prices and sunk costs determine managerial behavior. Second, to date, no other study has applied real options analysis to beets or sugar-based ethanol in the Untied States. Most existing real options applications in the biofuel industry have been generally limited to investments that are already in operation and are largely on corn ethanol. In order to address these limitations, this study relies on a unique database that is created using a combination of information on beet prices and plant-level cost analysis. In particular, results from the investment analysis give valuable information to potential investors and policy makers, given that policy interests regarding biofuel industry expansion are shifting toward 
the development of advanced biofuel plants. Furthermore, the analysis helps to illustrate the importance of ethanol and beet price volatility, sunk costs, and uncertainty, given that shutdown and temporary mothballing of active plants have been commonplace in the corn ethanol industry since late 2007 (Hertel and Beckman, 2012; Wisner, 2009), largely as a result of high feedstock prices and declining ethanol prices. For example, following the 2008 financial crisis, approximately $12 \%$ of the formerly operating production capacity was shut down (Wisner, 2009). At that time, about 15 to 18 plants were under construction but temporarily halted construction because of adverse economic conditions (Wisner, 2009). In 2013, out of 211, nearly $10 \%$ of ethanol plants temporarily suspended production as the 2012 drought tightened corn supply and the subsequent high corn prices made producing ethanol too expensive.

This study is based on a standard ROA and exposition of Dixit and Pindyck (1994). The methodological framework and some of the parametric assumptions follow from Schmit, Luo, and Tauer (2009) and Schmit, Luo, and Conrad (2011). To investigate the significance of the approach, this article develops a real options model to examine the basis for firms' entry and exit decisions and compares these trigger gross margins with break-even entry and exit gross margins to determine a price premium for risk and uncertainty. Sensitivity analysis on a range of possible ethanol gross margin volatility parameters, and sunk costs, is then conducted to explore how firm investment behavior is affected by a change in these parameters. The effect of managerial flexibility on the entry risk premiums and gross margins of ethanol that trigger mothballing, reactivation, and exit are also discussed. This article also evaluates hysteresis, the range of inaction in firm behavior that may arise as a result of the uncertainty in future gross margin values and irreversible investment. The investment analysis relies on the economics of a beet ethanol refinery facing typical market conditions in the northern plains of the United States. The empirical analysis is based on historical monthly ethanol and beet prices from 2000 to 2014 and recent surveys of operating and capital costs. We take historical sugar beet prices as a proxy for energy beet price, assuming that sugar beet prices can represent the future price of energy beets given that both crops have similar agronomic attributes and require the same cultural and management practices.

The next section develops the conceptual model for optimal entry, mothballing, reactivation, and exit. Then, Section 3 covers how data and stochasticprocess parameters are constructed. The empirical results are elucidated in Section 4, and Section 5 discusses the conclusions and implications of the study, guides for policy development, and directions for future research.

\section{Conceptual Framework and Empirical Specification}

The standard NPV investment decision rule is based on the Marshallian concept of the theory of entry and exit. The argument, under NPV assumptions, is that 
a firm will invest/enter in a specific market if the discounted net return is greater than or equal to the discounted operating cost plus capital expenditures. A firm will exit the market if the discounted net return falls below the discounted operating cost plus the net scrap value of selling the plant. The drawbacks of this methodology are that it ignores the opportunity cost of waiting for new information and assumes that future cash flows follow a constant pattern that can be accurately predicted. In effect, the NPV approach is not flexible when an investment is irreversible and the decision to invest can be postponed (Dixit, 1989; Dixit and Pindyck, 1994; Pindyck, 1991).

\subsection{Entry and Exit Strategies under Uncertainty: A Conceptual Framework}

There are three different states in which an ethanol refinery can be and five multiple switching options. The refinery states are idle, active, or mothballed. The switching options are idle to active, active to mothballed, mothballed to active, mothballed to exit (abandoned), and active to exit. The switching options this study evaluates include the following: (1) idle to active, (2) active to mothballed, (3) mothballed to active, and (4) active to exit.

In an idle state, a firm does not pay fixed or capital costs because the plant has not yet been built. An idle firm will invest when the demand conditions for output become sufficiently favorable, and an active firm will abandon the plant if demand becomes sufficiently adverse (Dixit and Pindyck, 1994). In this study, we assume that the firm incurs a lump-sum fixed cost $K$ to invest in an energy beet ethanol refinery. If the refinery decides to shut down (exit), there is a lump-sum exit/abandonment cost $l$ to close it. A refinery can recoup part of the investment cost $K$ upon exit, reflecting that part of $K$ is not fully sunk. Once the investment is made, the refinery generates a given flow of ethanol production until the plant is shut down. A refinery firm incurs a constant operating cost of $\omega$ to produce each unit of output. The ethanol refinery will generate a flow of operating profit equal to $P-\omega$ per period, where $P$ is the firm's ethanol gross margin (dollars per gallon). The ethanol gross margin is defined as the sum of ethanol and beet pulp prices minus beet price. The nonbeet operating cost $(\omega)$ is the sum of all operating costs less beet feedstock cost (dollars per gallon). Two possibilities exist: the ethanol refinery may be shut down if $P<\omega$ and later reactivated if $P>\omega$. This makes the ethanol refinery have an infinite sequence of instantaneous operating options, each of which is exercised if $P>\omega$ and can be valued accordingly (Dixit and Pindyck, 1994). Instead of abandoning, an ethanol refinery may choose to suspend operations and mothball, then later reactivate. In a mothballed state, a firm incurs an ongoing maintenance cost, $m$, to maintain existing capital. Mothballing requires a sunk cost per unit of expected output, $E_{m}$. In addition, the refinery can be reactivated in the future at an additional sunk cost, $r$. Finally, we assume $m<\omega$ for the mothballing option to be feasible.

The key variables to the investment decision in this particular investment analysis are ethanol gross margin and investment costs. The decisions to invest 
and exit are made assuming that the gross margin of ethanol is exogenous and stochastic and that it evolves according to geometric Brownian motion (GBM), described in equation (1):

$$
d P=\mu P d t+\sigma P d z
$$

where $P$ is the gross margin of the refinery, $\mu$ is an instantaneous drift in the gross margins of ethanol, $\sigma$ is the standard deviation or volatility of a given random increment to the gross margins of ethanol, and $d z$ is an increment to the standard Wiener processes for the uncertain variable and is uncorrelated across time $t$ and $d z=\sigma \sqrt{\Delta t}, E\left[d z^{2}\right]=d t$.

\subsubsection{The Decision to Enter}

The conceptual framework and the mathematical derivations of entry and exit decisions in this section are adapted from Dixit and Pindyck (1994) and Schmit, Luo, and Tauer (2009) and Schmit, Luo, and Conrad (2011). We assume that the value of a project is a function of the exogenous state variable (i.e., the gross margin of ethanol). Let $V_{0}(P)$ be the discounted expected value of an idle project or the option to invest. Similarly, $V_{1}(p)$ is the value for the active project. The solution consists of these functions and the rules for optimally switching between idle and active states. If the investors "sold" the refinery instead of deciding to invest, they would earn $V_{0}(P)$. Equilibrium in the asset market requires that

$$
\delta V_{0}(P)=\frac{E_{t}\left[d V_{0}(p)\right]}{d t},
$$

where $P$ is the gross margin of ethanol, $\delta$ is the discount rate, $\delta V_{0}(P)$ represents the normal return if the option to invest is sold, and $\frac{E_{t}\left[d V_{0}(p)\right]}{d t}$ is the expected capital gain from holding the option to invest. Equation (2) defines the entry trigger gross margin.

From Ito's lemma, for a function $V=V_{0}(P)$,

$$
d V=\left[V(P)+\mu P V_{0}^{\prime}(P)+0.5 P^{2} V_{0}^{\prime \prime}(P) \sigma^{2}\right] d t+\sigma P V_{0}^{\prime}(P) d Z,
$$

where $\mu$ and $\sigma$ are respectively the drift and standard deviation parameters of $P ; V_{t}=\partial V / \partial t=0$, given the infinite time horizon, $V_{0}^{\prime}=\partial V / \partial P, V_{0}^{\prime \prime}=\partial^{2} V / \partial P^{2}$, and $E[d Z]=0$. Simplifying equation(3) and substituting into equation(2) gives us the asset equilibrium condition represented by the differential equation:

$$
\delta V_{0}=\mu P V_{0}^{\prime}+\left(0.5 \sigma^{2}\right) P^{2} V_{0}^{\prime \prime} .
$$

The general solution for an idled firm for this homogenous second-order ordinary differential equation gives us:

$$
V_{0}(P)=A_{0} P^{-\alpha}+B_{0} P^{\beta}
$$

where $A_{0}$ and $B_{0}$ are unknown constants to be determined, and $\alpha$ and $\beta$ are the root mean of the quadratic equation parameters that capture and incorporate 
the uncertainty modeled by GBM into the model:

$$
\begin{gathered}
\beta=\frac{(1-m)+\left[(1-m)^{2}+4 g\right]^{1 / 2}}{2}>0 \\
-\alpha=\frac{(1-m)-\left[(1-m)^{2}+4 g\right]^{1 / 2}}{2}<0
\end{gathered}
$$

where $m=2 \mu \sigma^{-2}$ and $g=2 \delta \sigma^{-2}$, and for the convergence condition, $g>m$ implies that $\delta>\mu ; \delta$ is the discount rate. $A_{0} P^{-\alpha}$ and $B_{0} P^{\beta}$ capture the option value of switching to another state if margin $P$ changes. An idle project has no value if $P$ approaches zero; if $A_{0} P^{-\alpha}$ approaches zero, the first term in equation (5) vanishes. Because $-\alpha<0$ and $\beta>1$, this requires $A_{0}=0$ and simplifies equation(5), which gives the following solution to the differential equation:

$$
V_{o}(P)=B_{0} P^{\beta},
$$

where $V_{o}(P)$ is the value function of an idle investment and can be interpreted as the value of the option to enter.

\subsubsection{The Decision to Mothball}

If the gross margin of ethanol falls below $\omega$, instead of permanently abandoning the refinery, the refinery owner has the option to put the refinery into a state of temporary suspension, allowing it to be reactivated in the future at a sunk cost that is much less than the cost of building a new refinery.

Consider a refinery that is operating and earning instantaneous net revenue $(p-\omega)$. Let $V_{1}(p)$ denote the value function of the active refinery. Equilibrium conditions require that

$$
\delta V_{1}(P)=\frac{E_{t}\left[d V_{1}\right]}{d t}+(P-\omega)
$$

where $V_{1}(p)$ is the value function of an active refinery, and $\omega$ is the operating cost. The left-hand side is the normal return if the refinery is sold and proceeds invested at discount rate $\delta$. The right-hand side of equation (7) is the net revenue flow plus the expected capital gain. The derivation of the value of the active firm is done in a similar way to the idle firm, except that an active firm receives the flow of operating profit $(P-\omega) d t$, in addition to the expected capital gain. The general solution for an active refinery can be expressed as follows:

$$
V_{1}(p)=A_{1} P^{-\alpha}+B_{1} P^{\beta}+\left(\frac{P}{\delta-\mu}-\frac{\omega}{\delta}\right)
$$

where $A_{1}$ and $B_{1}$ are unknown constants to be determined, $A_{1} P^{-\alpha}+B_{1} P^{\beta}$ captures the option value of the mothballed refinery, and $P(\delta-\mu)^{-1}-\omega \delta^{-1}$ is the present value of the net cash flow. The value of the mothballing option 
goes to zero as $P$ gets very large, implying that $B_{1}=0$. Therefore, equation (8) becomes

$$
V_{1}(p)=A_{1} P^{-\alpha}+\left(\frac{P}{\delta-\mu}-\frac{\omega}{\delta}\right),
$$

where $A_{1} P^{-\alpha}$ represents the value of the option to mothball and $P(\delta-\mu)^{-1}-$ $\omega \delta^{-1}$ captures the expected present value of continuing production forever. The value of the mothballing option is derived from future possibilities of reactivation or abandonment. Note that an economically meaningful solution for $V_{0}$ must be nonnegative. Therefore, we must have $B_{1} \geq 0$ in equation (8). Similarly, an active firm has an expected value of $P(\delta-\mu)^{-1}-\omega \delta^{-1}$ from the feasible strategy of never shutting down. Also, in equation (9), we must have $A_{1} \geq 0$ (Dixit, 1989).

\subsubsection{The Decision to Reactivate and Exit}

Mothballing requires a sunk cost, $E_{m}$. In a mothballed state, the refinery requires maintenance at a cost of $m$. Let $V_{m}(p)$ denote the value function of the mothballed refinery with the option of reactivating or exiting. Equilibrium in the asset market requires that

$$
\delta V_{m}(P)=\frac{E_{t}\left[d V_{m}\right]}{d t}-m
$$

where the left-hand side is the normal return if the firm sells the mothballed refinery and invests the earnings at the discount rate of $\delta$, and the right-hand side is the expected capital gain of the mothballed refinery less ongoing maintenance costs. The resulting value function can be expressed as follows:

$$
V_{m}(p)=A_{m} P^{-\alpha}+B_{m} P^{\beta}-m \delta^{-1},
$$

where $A_{m}$ and $B_{m}$ are constants to be determined, $A_{m} P^{-\alpha}$ is the value of the option to reactivate the mothballed refinery, $B_{m} P^{\beta}$ is the value of the option to exit, and $m \delta^{-1}$ is the capitalized maintenance cost assuming that the refinery remains in the mothballed state forever. Mothballing only makes sense if the maintenance cost $(m)$ is less than the cost of actual operation and if the reactivation cost is less than the cost of reinvesting. The option value to exit is positive only if the gross margin decreases, and the option value to reactivate is positive only if the gross margin increases.

\subsubsection{Deriving Trigger Gross Margin}

For our representative ethanol refinery, four switching options are considered: from idle to active, active to mothballed, mothballed to active, and active to exit (abandon). At each switching option point, the value-matching and smoothpasting conditions must hold. Each of these options will be exercised at a specific gross margin value. Smooth-pasting conditions require tangency of the value functions at the respective trigger gross margins. 
For the active investment option, the value-matching and smooth-pasting conditions are, respectively,

$$
V_{o}\left(P_{h}\right)=V_{1}\left(P_{h}\right)-K \quad \text { and } \quad V_{o}^{\prime}\left(P_{h}\right)=V_{1}^{\prime}\left(P_{h}\right)
$$

where $P_{h}$ is the real options entry trigger gross margin. For mothballing, the value-matching and smooth-pasting conditions are, respectively,

$$
V_{1}\left(P_{m}\right)=V_{m}\left(P_{m}\right)-E_{m} \quad \text { and } \quad V_{1}^{\prime}\left(P_{m}\right)=V_{m}^{\prime}\left(P_{m}\right),
$$

where $V_{m}(P)$ is the value function of the mothballed refinery, and $P_{m}$ is the real options mothball trigger gross margin. For reactivation, the value-matching and smooth-pasting conditions are, respectively,

$$
V_{m}\left(P_{r}\right)=V_{1}\left(P_{r}\right)-r \quad \text { and } \quad V_{m}^{\prime}\left(P_{r}\right)=V_{1}^{\prime}\left(P_{r}\right)
$$

where $P_{r}$ is the real options reactivation trigger gross margin. At $P_{r}$, the value of the option to reactivate must equal the value of the active project minus the sunk cost of reactivation. Finally, for the exit option, the value-matching and smooth-pasting conditions are, respectively,

$$
V_{m}\left(P_{l}\right)=V_{o}\left(P_{l}\right)-l \quad \text { and } \quad V_{m}^{\prime}\left(P_{l}\right)=V_{o}^{\prime}\left(P_{l}\right),
$$

where $P_{l}$ is the real options exit trigger gross margin (dollars per gallon). At $P_{l}$, the value of the option to exit must equal the value of exiting less any sunk costs of exit.

Substituting the values of equations (6), (9), and (11) into the corresponding value-matching equations (12) through (15), and the derivative of the value functions with respect to $P$ into the smooth-pasting equations (12) through (15), results in a nonlinear system of eight equations with eight unknowns in equations (16) to (23). The first four equations constitute the value-matching conditions:

$$
\begin{aligned}
& B_{1} P_{h}^{\beta}-P_{h}^{\beta}(\delta-\mu)+\omega \delta^{-1}-A_{1} P^{-\alpha}=k, \\
& P_{m}(\delta-\mu)^{-1}-\omega \delta^{-1}+A_{1} P_{m}^{\alpha}=A_{m} P_{m}^{\alpha}+B_{m} P_{m}^{\beta}-m \delta^{-1}-E_{m}, \\
& A_{m} P_{r}^{\alpha}+B_{m} P_{r}^{\beta}-m \delta^{-1}=P_{r}(\delta-\mu)^{-1}-\omega \delta^{-1}+A_{1} P_{r}^{\alpha}-r, \\
& A_{m} P_{l}^{\alpha}+P_{l}^{\beta}(\delta-\mu)^{-1}-\omega \delta^{-1}=B_{1} P_{l}^{\beta}-l .
\end{aligned}
$$

The second corresponding four equations are derived from the smooth-pasting conditions:

$$
\begin{aligned}
& \beta B_{1} P_{h}^{\beta-1}=-P_{h}(\delta-\mu)^{-2}+\alpha A_{1} P_{h}^{\alpha-1} \\
& -P_{m}(\delta-\mu)^{-2}+\omega \delta^{-2}+\alpha A_{1} P_{m}^{\alpha-1}=\alpha A_{m} P_{m}^{\alpha-1}+\beta B_{m} P_{m}^{\beta-1}, \\
& \alpha A_{m} P_{r}^{\alpha-1}+\beta B_{m} P_{r}^{\beta-1}-m \delta^{-2}=-P_{r}(\delta-\mu)^{-2}+\alpha A_{1} P_{r}^{\alpha-1}, \\
& \alpha A_{m} P_{l}^{\alpha-1}+\beta B_{m} P_{l}^{\beta-1}=\beta B_{1} P_{l}^{\beta-1} .
\end{aligned}
$$


The previous eight equations (16-23) determine the four unknown trigger gross margins $\left(P_{h}, P_{m}, P_{r}\right.$, and $\left.P_{l}\right)$ and the four unknown scalar coefficients associated with the option value of switching states $\left(A_{1}, B_{1}, A_{m}\right.$, and $\left.B_{m}\right)$. The equations are nonlinear in the trigger gross margins and solved numerically. ${ }^{1}$ The trigger gross margins are endogenous and satisfy the condition $0<P_{l}<P_{b}$ $<\infty$, and the constant coefficients $A_{1}$ and $B_{1}$ are nonnegative. Moreover, $P_{r}<$ $P_{b}$ because the cost of reactivation is less than that of investing from scratch. An idle firm will find it optimal to remain idle as long as ethanol gross margins $(P)$ remain below $P_{h}$ and will invest as soon as $P$ moves above $P_{h}$. Moreover, an active firm will remain active as long as $P$ remains above $P_{l}$ but will abandon if $P$ falls to $P_{l}$. In the range of gross margins between the thresholds, $P_{l}$ and $P_{h}$, the optimal policy is to continue with the status quo, whether it be active operation or waiting. The discount rate $(\delta)$ must be greater than the drift rate $(\mu)$, otherwise it would never be optimal to invest because the growth rate would outpace the discount rate (Dixit and Pindyck, 1994).

\section{Data and Model Parameters}

The empirical model is based on a 20 million gallon per year (mgy) ethanol refinery that produces ethanol and two coproducts: beet pulp and stillage powder. Hence, the refinery obtains streams of revenue from the sale of ethanol and beet pulp per unit of energy beet processed. Processing energy beets into ethanol requires mechanical extraction of sugar, as opposed to the conversion of cellulose or starch into sugar prior to fermentation. Sugar from whole beets or extracted juice may be fermented into ethanol. Like corn starch ethanol, the process by which ethanol is produced from energy beets provides coproducts, such as pulp that may be sold as livestock feed and stillage powder for thermal heat generation (Asadi, 2007; Maung and Gustafson, 2011; Shapouri, Salassi, and Fairbanks, 2006; Wamisho, Ripplinger, and De Laporte, 2015). The mass balance of processing 1 ton of beets produces 26.5 gallons of ethanol and 0.05 tons of beet pulp and $0.0225 \mathrm{MMBTU} / \mathrm{gal}$. of stillage powder. To produce each gallon of ethanol, the refinery requires $0.0373 \mathrm{MBTU}$ of thermal energy and $0.6 \mathrm{kWh}$ of electricity. Thus, the refinery obtains $70 \%$ of its thermal energy requirement from using all of the stillage powder produced at the plant (Maung and Gustafson, 2011; Wamisho, Ripplinger, and De Laporte, 2015). Finally, at the $20 \mathrm{mgy}$ nameplate capacity, the annual feedstock demand is equated with the energy beet to ethanol conversion factor. With this, we assumed that the ethanol plant's demand for energy beet feedstock is fully met without shortage.

1 The system of equations is programmed in Matlab (R2014a). 
Table 1. Annual Operating Costs, 20 Million Gallon per Year Ethanol Plant

\begin{tabular}{ll}
\hline \hline Item & Dollars per Gallon \\
\hline Processing & 0.331 \\
Direct labor and benefits & 0.034 \\
Repairs, maintenance, materials, and services & 0.051 \\
Administrative, management, and other operating costs & 0.077 \\
Property taxes and insurance & 0.045 \\
Total nonbeet operating cost & 0.538 \\
\hline \hline
\end{tabular}

Note: Processing cost represents net processing cost after crediting $\$ 0.131 /$ gal. equivalent for the use of stillage powder generated in the plant.

Sources: Wamisho, Ripplinger, and De Laporte (2015), Maung and Gustafson (2011), and Green Vision Group (2014) project documents. Equipment prices were either obtained from the literature or provided by manufacturers through formal quotes.

\subsection{Operating and Investment Costs}

Operating costs comprise energy beet feedstock, processing including chemicals (denaturants, yeast and others), electricity, natural gas, stillage powder, makeup water and wastewater disposal, and labor, administration, and maintenance, among others. Net operating cost is computed after subtracting the value of coproduct sales and stillage powder from the total operating cost. Our cost breakdown shows that feedstock costs represent approximately $72 \%$ of the operating cost, implying that any change in the price of energy beets eventually affects operating costs. Hence, energy beet prices affect entry and exit prices. Table 1 contains baseline operating costs for our representative ethanol plant.

Capital investment costs $(K)$ comprise engineering and construction costs (e.g., equipment and tank packages, piping and mechanical, steel and enclosures, electrical and instrumentation, engineering, site development, rail, piler and other storage equipment, startup inventories, and other contingencies). Capital costs are calculated (\$3.18/gal.) as the present value of the investment costs. Details on capital cost are presented in Table 2. Our investment cost assumes $50 \%$ of loan financing of the total investment with a discount rate of $8.25 \%$. To satisfy the smooth-pasting conditions of the equalities, we assume that once the investment is made, an ethanol refinery produces a unit of output per period until abandoned.

For our baseline analysis, the value of each sunk cost is calculated as a percentage of the initial capital investment (Schmidt, Luo, and Tauer, 2009). We assume the liquidation/exit cost $(l)$, mothballing $\left(E_{m}\right)$ and reactivation $(r)$ are valued as $-25 \%, 5 \%$, and $10 \%$ of initial capital investment, respectively, and the maintenance cost $(m)$ in the mothballed state is valued at $2.5 \%$ of $K$. The baseline sunk costs per gallon of ethanol are as follows: $l=\$ 0.795, E_{m}$ $=\$ 0.159, r=\$ 0.318$, and $m=\$ 0.0795$. We assume that mothballing and reactivation costs comprise expenditures on wages and other costs paid in the 
Table 2. Investment Costs, 20 Million Gallon per Year Ethanol Plant

\begin{tabular}{ll}
\hline \hline Item & Dollars per Gallon \\
\hline Ethanol plant processing & 1.809 \\
Site development & 0.007 \\
Rail & 0.005 \\
Piler and other storage equipment & 0.565 \\
Storage excavation, gravel, concrete, and land & 0.646 \\
Contingency & 0.147 \\
Capital cost $(K)$ & 3.178 \\
\hline \hline
\end{tabular}

Sources: Wamisho, Ripplinger, and De Laporte (2015), Maung and Gustafson (2011), and Green Vision Group (2014) project documents. Equipment prices were either obtained from the literature or provided by manufacturers through formal quotes.

process of mothballing and reactivation. Preparation costs to sell the plant and clean up the site upon shutting down the refinery permanently are assumed to be negligible and not included in the cost. All costs are assumed to be constant in real terms.

The gross margin of beet ethanol is calculated as the sum of ethanol and beet pulp prices minus the beet price. To compute the gross margin, we convert the sugar beet and beet pulp prices into a dollars per gallon of ethanol equivalent using a conversion rate of 26.5 gallons of ethanol and 0.05 ton of beet pulp produced per ton of energy beets (Maung and Gustafson, 2011 ; Wamisho, Ripplinger, and De Laporte, 2015). Whereas the stillage powder is credited back into the operating cost, ethanol prices are computed by averaging monthly ethanol prices from January 2000 to December 2014 from the Nebraska Energy Office (2015), representing rack (wholesale) prices (free on board [FOB] price, Omaha, Nebraska). The data for sugar beet prices are obtained from the Farm Financial Database (FINBIN), representing the average value of sugar beets for North Dakota and Minnesota form 2000 to 2014 (FINBIN, 2016). The beet pulp price is from monthly prices representing the Minneapolis market (USDA, 2016).

\subsection{Stochastic Gross Margin Parameters}

In this section, we estimate the gross margin stochastic parameters. The random variable considered in this study is the ethanol gross margin.

Our data show that ethanol prices were in the range of $\$ 1$ to $\$ 2$ per gallon between 2000 and 2004. After 2005, the ethanol price increased steadily, with the exception of a downward blip in 2009 and 2010. The monthly ethanol price peaked in July 2006 at nearly $\$ 3.58$ per gallon and in April 2014 at $\$ 3.15$ per gallon. In order to investigate the impact of increasing price volatility starting in late 2006 (see Figure 1), we split the sample into two periods: the full sample period from January 2000 to December 2014 and the subsample period from 


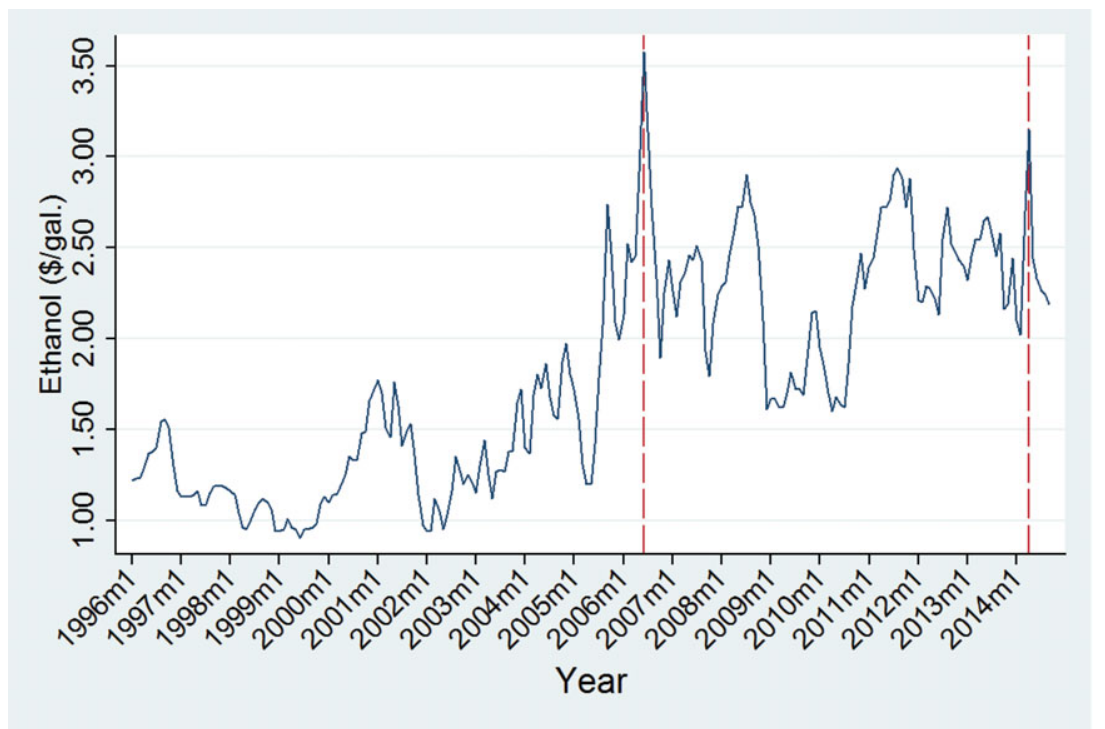

Figure 1. Historical Monthly Ethanol Rack Price at Omaha, Nebraska

Table 3. Augmented Dickey-Fuller Test for Unit Root

\begin{tabular}{lllll}
\hline \hline Sample Period & Test Statistics & $1 \% \mathrm{CV}$ & $5 \% \mathrm{CV}$ & $10 \% \mathrm{CV}$ \\
\hline Full data period & 3.43 & 3.48 & 2.89 & 2.58 \\
Subsample data period & 2.77 & 3.51 & 2.89 & 2.58 \\
\hline \hline
\end{tabular}

Notes: Full sample period represents data from January 2000 to December 2014, and subsample period is from August 2006 to December 2014. CV represents critical value.

August 2006 to December 2014. The drift and volatility parameters for these subsample periods are calculated.

The gross margins are deflated into real terms using the urban consumer price index (U.S. Department of Labor, 2010). An augmented Dickey-Fuller (ADF) test is applied to determine if the evolution of gross margins follows a random walk or has a unit root. The ADF unit root test results (Table 3) show that we cannot reject the null hypothesis that log of gross margin $(\ln P)$ exhibits a unit root at the $99 \%$ and $95 \%$ confidence level.

Choosing the appropriate stochastic process for modeling commodity prices should also be based on theoretical consideration in addition to the statistical test results (Dixit and Pindyck, 1994). In addition, Schmit, Luo, and Tauer (2009), Schmit, Luo, and Conrad (2011), and Gonzalez, Karali, and Wetzstein et al. (2012) found no evidence of mean reversion in U.S. ethanol prices. These authors argue that ethanol price is better modeled using GBM than mean reversion. As such, Postali and Pichcetti (2006) show that crude oil prices reasonably follow 
Table 4. Regression Results and Parameters of Gross Margins

\begin{tabular}{lll}
\hline \hline Parameter & Full Sample & Subsample \\
\hline $\operatorname{Ln}\left(P_{t}-1\right), \beta$ & $-0.132^{* *}(0.037)$ & $-0.115^{* *}(0.045)$ \\
Drift rate, $\mu$ & -0.015 & -0.037 \\
Volatility, $\sigma$ & 0.483 & 0.277 \\
\hline \hline
\end{tabular}

Notes: Standard errors in parentheses. Plus sign indicates significance at the 0.10 level. Asterisks $\left({ }^{*},{ }^{* *}\right.$, and $\left.{ }^{* * *}\right)$ indicate significance at the $0.05,0.01$, and 0.001 level, respectively.

GBM and are strongly correlated with ethanol prices. In fact, Dixit and Pindyck (1994) argue that commodity prices are shown to exhibit GBM and typically require many years of data to determine with any degree of confidence whether a variable certainly follows mean reversion. Given the ADF test result and having shorter sample data periods, the stochastic variables used in our real option analysis are assumed to evolve according to GBM. Hence, we assume that the gross margin of ethanol evolves exogenously over time through GBM as in equation (1), which is the continuous-time formulation of the random walk. As a result, $\ln P$ follows a Brownian motion with drift parameter $\mu=\beta-\frac{1}{2} \sigma^{2}$ and volatility $\sigma$. The total derivative of $\ln P$ is the following:

$$
d \ln P=\left(\beta-\frac{1}{2} \sigma^{2}\right) d t+\sigma d z
$$

where $P$ is the gross margin and $\beta$ contains the parameters to be estimated. GBM requires $d \ln P$ to have a unit root, and our resulting series are nonstationary. To remedy this problem, the drift and volatility parameters are computed as the sample mean and standard deviation of the first difference of the natural $\log$ of the annual gross margin series. Note that in some months the gross margins are less than zero. To avoid negative values, we vertically scaled up the gross margins by $\$ 0.14 /$ gal. for all data points before we ran the regression. ${ }^{2}$ We recovered stochastic parameters displayed in Table 4 using ordinary least squares by regressing $\Delta \ln P$ on an intercept term and lagged values $\Delta \ln P_{t-1}$.

Because the investment analysis is based on annual production, the baseline solutions of real options trigger gross margins are calculated after converting monthly parameters to annual equivalents assuming that both the drift rate and variance of the increments of a Brownian motion are linear in time. For the full data period model, January 2000 to December 2014, the annual drift and volatility parameters are -0.015 and 0.483 , respectively, and for the subsample period of August 2006 to December 2014, these parameters are -0.037 and 0.277 , respectively (Table 4). The gross margin volatility parameters evolve directly from the root-mean-square error estimation results. Although correlation among all cost and revenue variables certainly determines investment behavior

2 Shifting the data vertically is a common approach (for details, see Schmit, Luo, and Conrad, 2011). 
relative to entry and exit decisions, the lack of stochastic data specifically on beet ethanol investment cost and other operating costs do not allow us to capture correlated uncertainty in empirical specification. Therefore, we assume that the magnitude of other operating, investment, mothballing, and reactivation costs are constant, not stochastic.

\section{Results and Discussion}

The empirical results are presented in two distinct sections. Section 4.1 discusses the results from the baseline solution, along with a comparison of the baseline results with those from the Marshallian approach. Section 4.2 contains results from comparative static and sensitivity analysis to explore how the gross margin trigger value varies with a change in stochastic parameters and underlying investment variables. To conduct the comparative static analysis, we ran a sensitivity analysis to explore the effects of a change in volatility parameters. In addition, we considered how a change in liquidation and reactivation costs could potentially affect the exit and entry decisions for a given level of stochastic parameters.

The Marshallian/NPV entry gross margin is calculated using $W_{h}=\omega+$ $\delta K$, where the right-hand side of the equation is the annualized full cost of making and operating the investment. Conversely, the exit gross margin is computed as $W_{l}=\omega-\delta K$. Thus, the full cost $\omega+\delta K$ serves as the entry trigger, and the nonbeet operating cost $\omega$ as the exit trigger gross margin threshold for making an investment decision. This is the standard Marshallian theory of the long run versus the short run, based on the gap between the full and variable costs (Dixit and Pindyck, 1994). Under the Marshallian approach, at gross margins between $W_{h}$ and $W_{l}$, an idle firm does not invest and an active firm does not exit. However, the firm will abandon the project if the gross margin of ethanol is less than the nonbeet operating cost.

\subsection{Baseline Results}

Using the parameters from the two sample periods, the real options trigger gross margins are calculated with and without mothballing and reactivation options. ${ }^{3}$ Table 5 presents the calculated baseline trigger gross margins under real options and the Marshallian approach.

Using the full sample data, the baseline real options entry gross margin estimate is $\$ 1.84 /$ gal., approximately $57 \%$ higher than the corresponding Marshallian gross margin of $\$ 0.80 / \mathrm{gal}$, and the real options exit gross margin is $\$ 0.32 /$ gal., $19 \%$ smaller than the Marshallian exit price of $\$ 0.47 /$ gal. The inaction gap, between the real options entry and exit gross margins, is $\$ 1.53 /$ gal.,

3 The real options entry and exit gross margins estimate without mothballing and reactivation options are similar to the results with mothballing and reactivation options that are displayed in Table 5 . 
Table 5. Baseline Real Options Trigger Gross Margins, Dollars per Gallon

\begin{tabular}{lll}
\hline \hline Variable & Full Model & Subsample Model \\
\hline Entry margin, $P_{h}$ & 1.84 & 1.59 \\
Reactivation margin, $P_{r}$ & 0.87 & 0.77 \\
Mothballing margin, $P_{m}$ & 0.28 & 0.34 \\
Exit margin, $P_{l}$ & 0.32 & 0.45 \\
Entry margin $(\mathrm{NPV})$ & 0.80 & 0.80 \\
Exit margin $(\mathrm{NPV})$ & 0.47 & 0.47 \\
\hline \hline
\end{tabular}

Notes: With managerial flexibility implies entry and exit with mothballing and reactivation options, whereas without managerial flexibility (i.e., inflexible option) represents entry and exit without mothballing and reactivation options. The empirical results show that having the managerial flexibility of mothballing and reactivation does not change the trigger entry and exit gross margins. NPV, net present value.

which is significantly higher than the corresponding entry and exit gap under the Marshallian approach, $\$ 0.33 /$ gal. This is an indication that hysteresis is significant and the optimal thresholds with rational expectations of ROA are spread farther apart than the Marshallian ones with static expectations of NPV. The NPV-based gross margins range between \$0.8/gal. and \$0.47/gal. In this range, an idle firm does not invest and an active firm does not exit. On the exit side, the trigger exit gross margin is $\$ 0.47 /$ gal., which is just below the net nonbeet operating cost of $\$ 0.54 / \mathrm{gal}$., an indication that once the investment is made, the firm will not abandon the project unless the exit gross margin is sufficiently far less than the net operating cost.

A further real options analysis using the subsample data period, 2006-2014, shows that the inaction gap between the real options entry and exit margin is $\$ 1.53 / g a l .$, which is smaller than under the full sample data (Table 5). Using the subsample period, the ROA entry threshold margin is found to be $\$ 0.25 / \mathrm{gal}$. less than the value obtained under the full sample period. The exit threshold margin also increases $\$ 0.13 /$ gal., indicating that as future uncertainty decreases so does the firm's inaction gap.

The drift rate is a trend rate of growth in the gross margins of ethanol, and a positive and increasing drift rate is expected to improve the profitability of the ethanol investment. However, drift rate values in our study are negative in both sample periods, indicating that, in the long-run, there is a potential decline in ethanol gross margins. As depicted in Table 4, volatility parameters in our subsample period are smaller than that in the full sample period. The difference in these parameter values has implications for the threshold behavior of the firm. Given our negative drift rates and comparing the two baseline solutions in Table 5, an idle ethanol firm waits longer to invest and requires a higher threshold gross margin as the volatility of gross margins increases, whereas an active firm is more reluctant to exit the ethanol market once invested. In the 
next section, we explore in detail how trigger gross margins change for different values of volatility parameters.

We found that mothballing trigger gross margins were $\$ 0.28 / \mathrm{gal}$. and $\$ 0.34 /$ gal., relatively less than the exit gross margins of $\$ 0.32 /$ gal. and $\$ 0.45 /$ gal., indicating that the owner of the biorefinery prefers to exit directly, rather than mothballing. This makes sense given that a mothballed state requires the firm to incur additional maintenance costs to keep the plant ready for future reactivation. For mothballing to be an optimal strategy, the trigger mothballing gross margin must be greater than the exit margin (Dixit and Pindyck, 1994). In addition, the model results show that to switch from a mothballed to an active state, the gross margin of ethanol must be $\$ 0.871 /$ gal. or $\$ 0.77 /$ gal., in the sample and subsample, respectively.

\subsection{Competitiveness of Energy Beet-Based Ethanol}

One way to evaluate the competitiveness of energy beet ethanol relative to conventional corn ethanol is to compare real options and Marshallian gross margin results from our model to the actual monthly gross margins of corn ethanol. An illustration of historical corn ethanol gross margins is overlaid onto the real options and Marshallian trigger gross margins we find in this study (Figures 2 and 3). These figures provide an intuitive way to compare estimated real options entry and exit gross margins with historical corn ethanol gross margins. In addition, the beet ethanol margins are also calculated based on historical beet and corn ethanol prices and overlaid along with corn ethanol gross margins (Figures 2 and 3). Although energy beet ethanol has not yet been produced, studying potential beet ethanol gross margins illustrates how future beet ethanol gross margins could change, should beet and ethanol stochastic prices follow past price evolution processes.

Our baseline real options entry gross margin is above the historical actual gross margin of corn and beet ethanol for only a small period, an indication that there were few time periods that would have supported beet ethanol plant investment (Figure 2). We counted the number of months in which the real options trigger gross margin is less than that of historical ethanol gross margins. Out of the 180 months studied, there are only 7 months (time periods) that the real option entry trigger gross margin ( $\$ 1.84 /$ gal. $)$ is less than that of actual corn ethanol gross margins. These 7 months occur after the year 2005, the time period in which the ethanol price was above $\$ 2 /$ gal. The number of time periods rose to 11 when we compared with energy beet ethanol gross margins. However, the Marshallian NPV entry trigger margin (\$0.8/gal.) would have signaled investments in energy beet ethanol in many time periods given that its value is greater than that of ethanol gross margins. On the exit side, there were quite a number of time periods that would have supported a plant exit.

For further examination into the competitiveness of beet ethanol investments, we again chose past gross margin regimes that represent time periods in which 


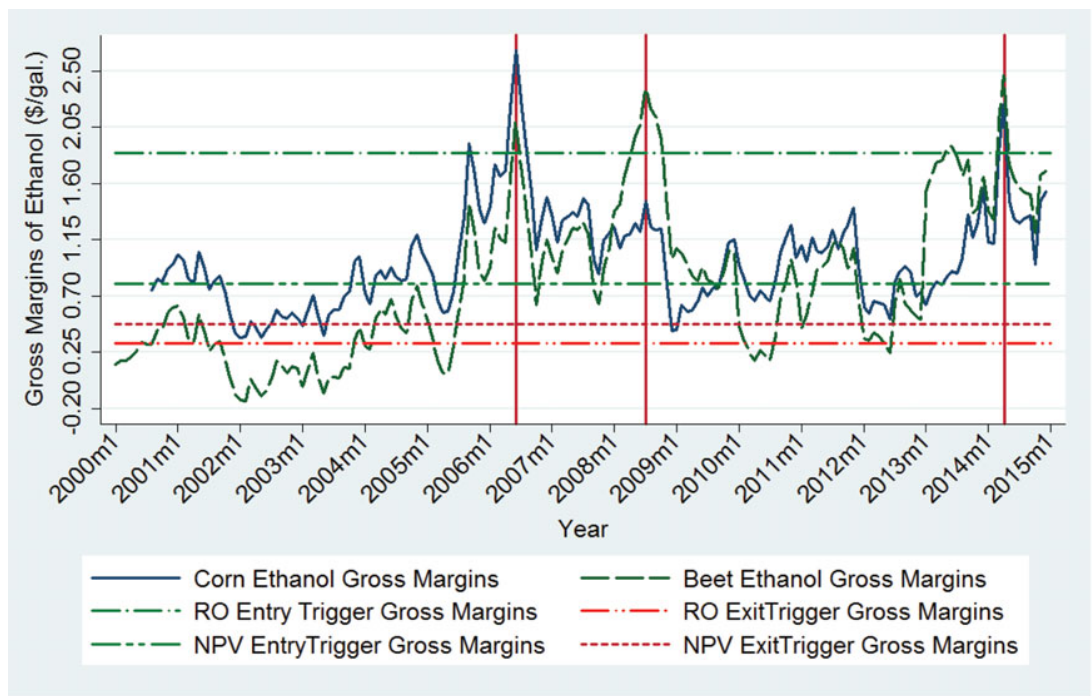

Figure 2. Real Options (RO) and Net Present Value (NPV) Entry and Exit Trigger Gross Margins Overlaid by Historical Corn and Beet Ethanol Gross Margins, Using the Full Sample Data (note: the horizontal lines represent the RO and NPV entry and exit trigger gross margins calculated as baseline solutions using the full sample data period [see Table 4]; the vertical lines inside Figure 2 are drawn on June 2006, August 2008, and April 2014)

a number of new corn ethanol plants entered the U.S. ethanol market. Figure 3 depicts the later periods of gross margins and the baseline real options trigger margins obtained under the subsample period. The gross margins of the corn and beet ethanol tend to follow similar upward and downward trends. However, as is apparent at times, the gross margins across a few time periods diverge from each other, an indication of the differences in corn and beet feedstock prices. Figure 3 again illustrates that there are few time periods that signal investments in energy beet ethanol.

It is apparent that narrower gross margins could potentially tighten plant profitability, and, in the long run, this condition decreases the value of the ethanol plant. In addition, the biorefinery owner will abandon at a higher threshold exit price because the plant will lose more money when gross margins tighten. As such, the expected flow of profit from, and hence the option value of, the plant falls as the beet ethanol gross margin decreases, implying that higher ethanol prices and/or lower beet prices are required before the firm is willing to invest. Moreover, higher operating costs reduce the value of operating an ethanol refinery, raise the trigger reactivation prices at which a mothballed plant could be reactivated, and raise the mothballing and reactivation price thresholds. 


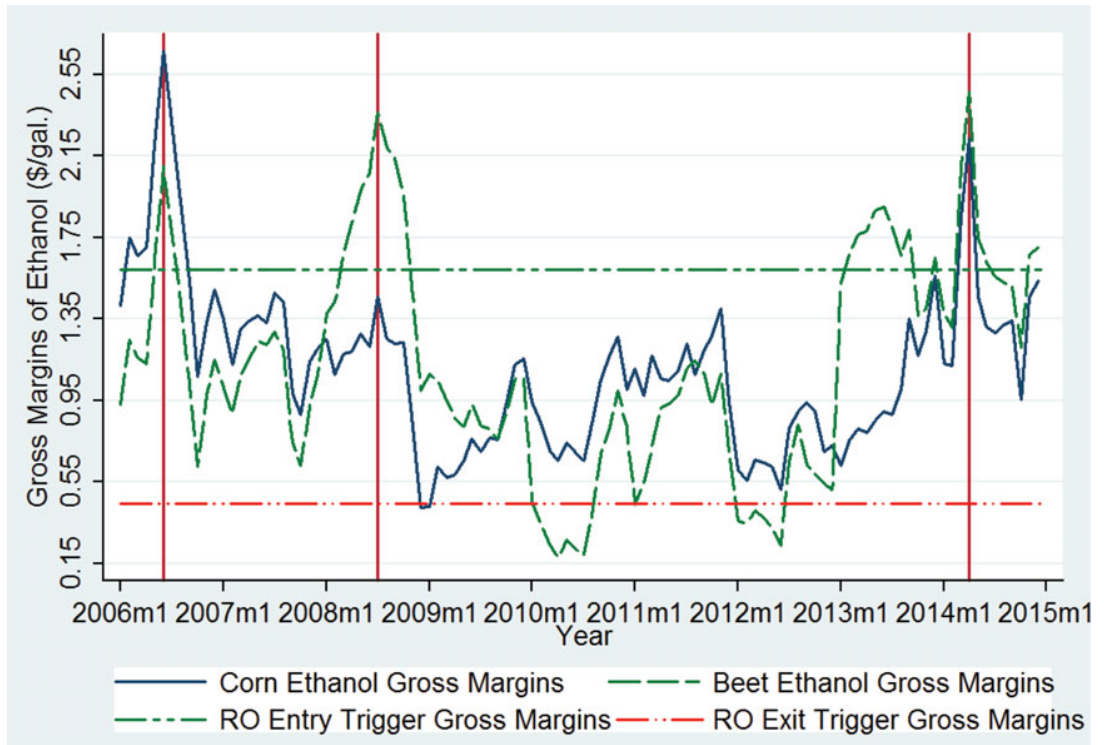

Figure 3. Real Options (RO) and Net Present Value (NPV) Entry and Exit Trigger Gross Margins Overlaid by Historical Corn and Beet Ethanol Gross Margins, Using the Subsample Data (note: the horizontal lines represent the RO entry and exit trigger gross margins, \$1.59/gal. and \$0.45/gal., respectively, calculated as baseline solutions using subsample data period [see Table 4]; the three vertical lines inside Figure 3 are drawn on June 2006, August 2008, and April 2014)

\subsection{Effects of Ethanol Gross Margin Volatility}

In this section, we present the results from the sensitivity analysis by taking different volatility parameters of ethanol gross margins using a full sample data period. The sensitivity analysis examines $5 \%$ incremental increases in the volatility of gross margins from $10 \%$ to $60 \%$, keeping $\beta$, the discount rate parameter, and sunk and other unit net operating costs constant. Figure 4 shows how trigger gross margins evolve with a change in ethanol gross margin volatility. The vertical line inside Figure 3 is drawn onto the baseline volatility, $\sigma=0.48$, and the corresponding real options trigger gross margins. If there is relatively insignificant uncertainty over the future gross margin of ethanol, $\sigma=0.1$, the trigger entry and exit gross margin will be $\$ 1.56 /$ gal. and $\$ 0.59 /$ gal., respectively. With a modest change in volatility, for example, a change from 0.1 to 0.15 , the zone of inaction (i.e., the distance between the entry and exit trigger gross margins) increases from $\$ 0.98 /$ gal. to $\$ 1.1 /$ gal., implying that even a small increase in uncertainty affects trigger gross margins. 


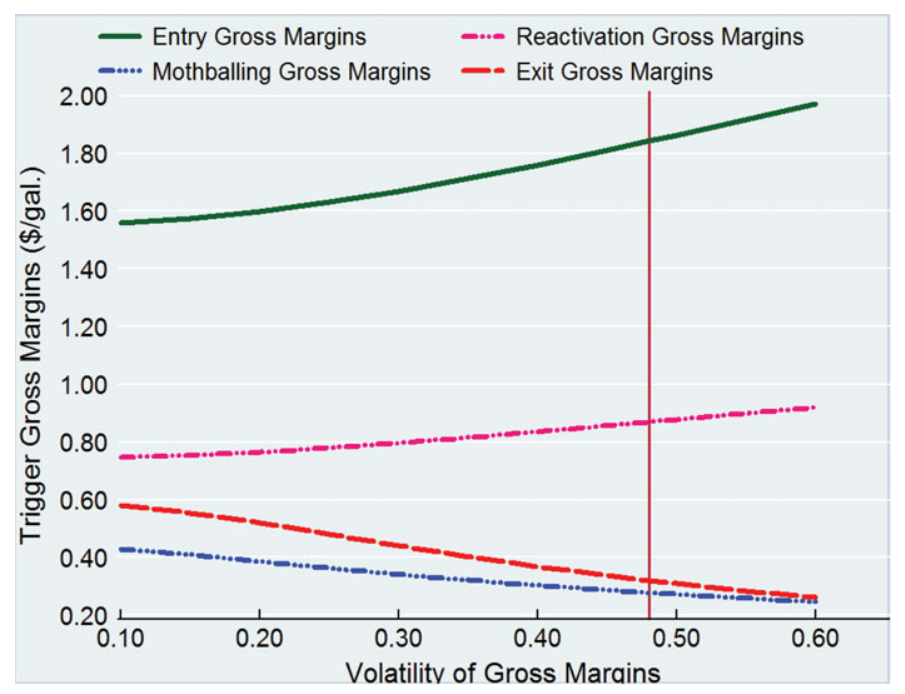

Figure 4. Real Options Trigger Gross Margins Relative to Changes in Volatility of Ethanol Gross Margins, Using Full Sample Data Parameters

The zone of inaction widens substantially to $\$ 1.71 /$ gal. for larger values of $\sigma$ $(=0.60)$. The gap between entry and exit gross margins increases as the volatility parameter increases, indicating that hysteresis remains significant even for small changes in ethanol gross margin volatility. Overall, as the volatility of gross margins increases, beet ethanol firms prefer waiting longer to invest. However, once an investment is made, managers in the active state prefer to wait longer before shutting down even if margins are falling. In addition, an increase in gross margin volatility increases the trigger reactivation gross margins in which a mothballed plant is reactivated.

On the mothballing side, at relatively low levels of uncertainty, mothballing trigger gross margins are less than the corresponding exit margins, and the gap between both margins (the range of inactivity) is large. However, mothballing trigger gross margins subsequently start to converge to the exit margins, just passing the baseline value of volatility (Figure 4). With the range of volatility parameters we use, the probability of a sufficiently large increase in gross margins of ethanol is too small to make mothballing economical and a plant will be better off exiting and avoiding the maintenance costs associated with a mothballed state. For mothballing to be an optimal strategy, the trigger real options mothballing gross margin must be greater than the exit margin (Dixit and Pindyck, 1994).

In general, our results show that relatively stable gross margins induce trigger entry gross margins to fall. Once the investment is made, the firm is more willing to stay operating despite there being adverse gross margins temporarily. 


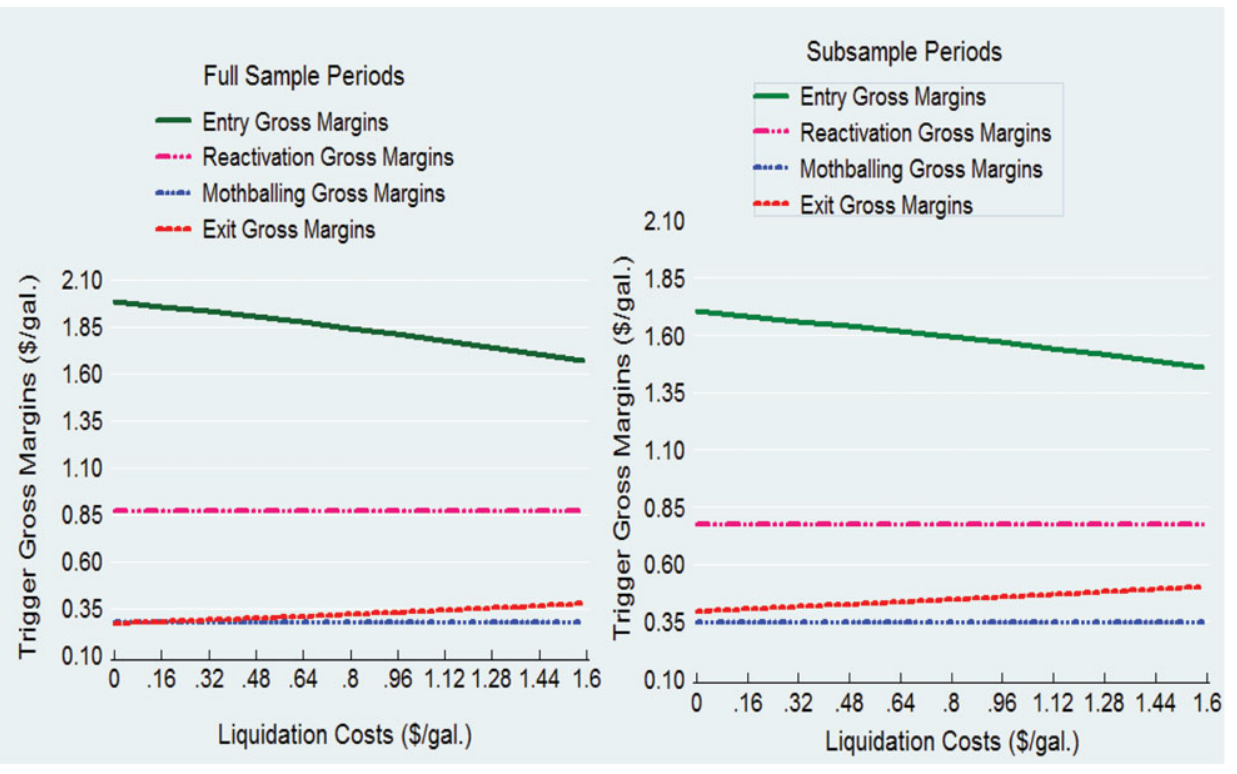

Figure 5. Real Options Entry and Exit Trigger Prices Relative to Changes in Liquidation Costs

\subsection{Effects of Liquidation and Reactivation Costs}

We further ran sensitivity analysis to explore the effects of liquidation and reactivation costs on trigger gross margins. Liquidation and reactivation costs are simulated in $5 \%$ increments and decrements from baseline values. The two panels in Figure 5 show how trigger gross margins evolve with a change in liquidation and reactivation costs based on the full and subsample data sets. Our empirical results from a full sample period show that entry and exit trigger gross margins are around \$1.99/gal. and \$0.27/gal., respectively, if an active firm is not able to recoup any of the capital investment (i.e., zero liquidation cost upon exiting ethanol market). However, these trigger gross margins are $\$ 1.62 /$ gal. and $\$ 0.39 /$ gal., respectively, when the liquidation cost is $50 \%$ of $K$. For exposition, if the liquidation cost is zero, the trigger entry and exit gross margins are $\$ 1.7 /$ gal. and $\$ 0.39 /$ gal., respectively, using the subsample data period. As Figure 5 illustrates, the real options entry trigger gross margins in the subsample period are less than the corresponding entry margins in the full sample period, whereas exit trigger gross margins are otherwise for all values of liquidation used in our sensitivity analysis. As such, the variation in trigger margins between the two data periods is as a result of differences in the volatility parameter. These results assert that, if an active firm foresees that it is able to recover more of its initial capital investment, it is willing to invest at relatively lower gross margins, but at the same time, more quickly prefer the exit option. 

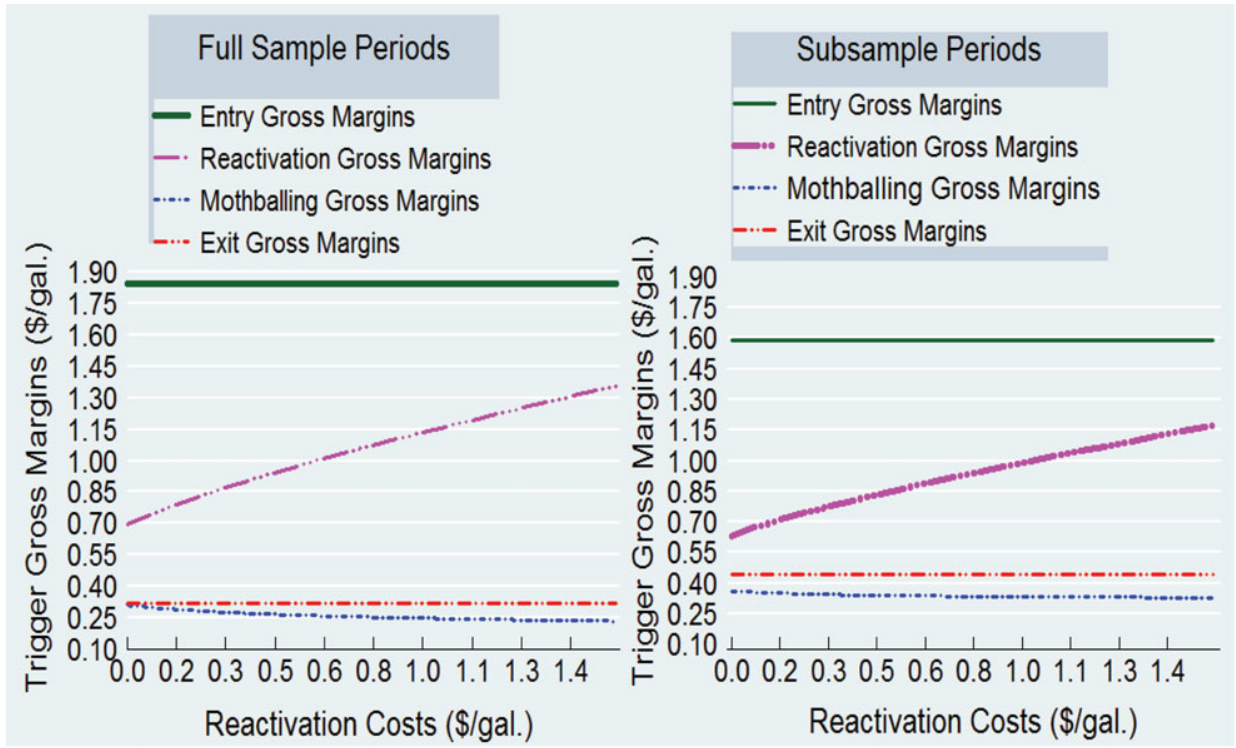

Figure 6. Real Options Entry and Exit Trigger Prices Relative to Changes in Reactivation Cost

The empirical results show that trigger mothballing and reactivation gross margins do not change with a change in liquidation costs. However, as shown in the left panel of Figure 5, mothballing is part of the firm's optimal strategy if liquidation costs are close to zero. For liquidation values greater than $\$ 0.16 / \mathrm{gal}$., it is optimal for the plant owner to exit directly, thereby recouping some amount of the initial capital, rather than switching to a mothballed state. Therefore, the $\$ 0.16 /$ gal. liquidation cost, where these two trigger margins converge, defines the boundary of the liquidation cost space where mothballing ceases to be relevant. Although mothballing is part of the optimal strategy, it only makes sense if the maintenance costs at the mothballed state are less than the net actual operating costs of the ethanol refinery and if the reactivation cost is less than the cost of fresh investment (Dixit and Pindyck, 1994).

With regard to reactivation gross margins, margins are not changed at all for each change in liquidation costs as depicted in Figure 6. Our results show that firms mothball active plants less readily.

To this end, mothballing is not an optimal strategy in almost all of the sensitivity analysis because mothballing is useful only if there is a reasonable probability of a substantial increase in revenue in the near future. The real options trigger reactivation gross margins increase with an increase in reactivation costs, implying that firms will reactivate a mothballed plant more readily if the reactivation cost is smaller. 


\section{Conclusions and Implications of the Findings}

This study explores how the decision to invest in a new energy beet ethanol refinery could be affected by ethanol and beet market price uncertainties and underlying irreversible investments. We analyze the optimal rules for exercising the option to invest, mothball, and exit in terms of underlying ethanol and beet price volatility and sunk costs associated with each state of the refinery.

The empirical results show that higher ethanol gross margin volatility causes firms to wait longer before entering and, once active, wait longer before exiting. Hysteresis (inaction) between entry and exit increases with higher levels of ethanol gross margin uncertainty, implying that investment in a new refinery is made more reluctantly, but once made, abandonment is not exercised easily. Under higher levels of gross margin volatility, an active firm waits longer to mothball, and a mothballed firm waits longer to reactivate. Moreover, the expected value of the ethanol biorefinery falls sharply as gross margins shrink, indicating that higher gross margins are required before the firm is willing to invest, and the firm abandons the plant at a higher threshold exit price. With the exception of liquidation costs, trigger gross margins do not rise and fall by very large values with changes in sunk and reactivation costs, suggesting that investment is highly sensitive to volatility in the market gross margin of ethanol and beets, irrespective of owners' risk preferences and irrespective of the extent to which the riskiness of the project value is correlated with the market. The sensitivity analysis shows that volatility in gross margins of ethanol has much greater effects on exit and entry trigger gross margins and ethanol plant values than investment costs. Empirical results indicate that uncertainty about ethanol prices, beet prices, and sunk costs are important determinants of energy beet investment behavior. We observe that all of the real options trigger margins are quite sensitive to gross margin volatility.

In general, our empirical results demonstrate that the prospect of beet ethanol plant entry into U.S. ethanol markets, and being competitive with conventional corn ethanol, seems uncertain given that the trigger entry gross margins we computed are significantly higher than the gross margins of conventional ethanol. Given the outlook of the current ethanol market situation, uncertainty about beet feedstock costs, coupled with volatility in ethanol prices and higher plant investment costs, poses a significant barrier to investment in energy beet ethanol plants of the scale examined here.

As such, our model results imply that the emergence of energy beet ethanol is unlikely considering the current ethanol market conditions, in part because of strong competition from conventional ethanol and costly beet feedstock. Albeit, one way to make beet ethanol more attractive to investors is through government subsidies. Historical rapid growth in the U.S. ethanol industry has been driven by various incentives and mandates placed on biofuel industries (Babcock, Marette and Tréguer, 2010; Epplin et al., 2007; Wetzstein, 2010). For example, Schmit, 
Luo, and Conrad (2011) found that in the absence of ethanol policies, much of the recent expansionary period would not have existed, and some plant closures would have been imminent given the past market conditions. Yi, Lin, and Thome (2015) found that the RFS is a critically important policy for supporting the sustainability of corn-based fuel ethanol production, and that investment and entry subsidies are more effective than production subsidies. As in the United States, ethanol investment decisions in Europe are affected more by government policies and strategic interactions than by economic factors such as ethanol prices, natural gas prices, and feedstock prices (Yi and Lin Lawell, 2016).

We can argue that the future investment outlook for energy beet ethanol might be more promising and enhanced if ethanol market conditions improve, beet to ethanol conversion technologies become more favorable, and policy interventions in the form of subsidies occur.

Our analysis does not include any federal or state ethanol subsidies or tax incentives, which may change the value of trigger prices. Such policies usually change trigger entry and exit prices by reducing uncertainty and perceived investment risk. From the perspective of beet ethanol investors, the policy uncertainty surrounding the formal designation of beet ethanol as an advanced biofuel is a key factor in investment decision making, in addition to price uncertainty and investment costs. Moreover, obtaining constant beet feedstock supply may be challenging given that energy beet is bulky to transport and its sucrose content quickly deteriorate unless it is transported and processed fairly quickly.

Ethanol from energy beets could play a key role in meeting some of the objectives of the RFS at a time when progress on cellulosic ethanol lags behind proposed schedules and the mandated volumetric requirement under the RFS. Our results may provide a useful tool for potential beet ethanol investors considering investment decisions and for policy makers interested in the development of renewable energy and small-scale industry in rural America.

\section{References}

Asadi, M. Beet-Sugar Handbook. Hoboken, NJ: John Wiley and Sons, 2007.

Babcock, B.A., S. Marette, and D. Tréguer. "Opportunity for Profitable Investments in Cellulosic Biofuels.” Energy Policy 39,2(2011):714-19.

Brennan, M.J., and E.S. Schwartz. "Evaluating Natural Resource Investments.” Journal of Business 58,2(1985):135-57.

Cai, X., and K.W. Stiegert. "Market Analysis of Ethanol Capacity." International Food and Agribusiness Management Review 17,1(2014):83-94.

Cook, J.A., and C.-Y.C. Lin Lawell. "Wind Turbine Shutdowns and Upgrades in Denmark: Timing Decisions and the Impact of Government Policy." Working paper, Davis: University of California, Davis, September2015. Internet site: http://www. des.ucdavis.edu/faculty/Lin/DKwind_paper.pdf (Accessed Septmber 28, 2015). 
Coyle, W.T. Next-Generation Biofuels: Near-Term Challenges and Implications for Agriculture. Washington, DC: U.S. Department of Agriculture, Economic Research Service, BIO-01-01, May 2010. Internet site: http://www.ers.usda.gov/media/ 122837/bio0101.pdf (Accessed September 30, 2014).

Dixit, A. "Entry and Exit Decisions under Uncertainty." Journal of Political Economy 97,3(1989):620-38.

Dixit, A.K., and R.S. Pindyck. Investment Under Uncertainty. Princeton, NJ: Princeton University Press, 1994.

Epplin, F.M., C.D. Clark, R.K. Roberts, and S. Hwang. "Challenges to the Development of a Dedicated Energy Crop." American Journal of Agricultural Economics 89,5(2007):1296-302.

FINBIN, Farm Financial Database. “Crop Summary Reports.” University of Minnesota. Internet site: https://finbin.umn.edu/ (Accessed August 29, 2016).

Gallagher, P., H. Shapouri, and H. Brubaker. "Scale, Organization, and Profitability of Ethanol Processing." Canadian Journal of Agricultural Economics 55,1(2007):6381.

Gonzalez, A.O., B. Karali, and M.E. Wetzstein. “A Public Policy Aid for Bioenergy Investment: Case Study of Failed Plants.” Energy Policy 51(December 2012):465-73.

Green Vision Group. “The Energy Beet Project.” Fargo, ND: Green Vision Group, 2014.

Hertel, T.W., and J. Beckman. "Commodity Price Volatility in the Biofuel Era: An Examination of the Linkage between Energy and Agricultural Markets.” The Intended and Unintended Effects of U.S. Agricultural and Biotechnology Policies. National Bureau of Economic Research Conference Report. J.S. Graff Zivin and J.M. Perloff, eds. Chicago: University of Chicago Press, 2012, pp. 189-221.

Kulatilaka, N. “The Value of Flexibility.” Working paper MIT-EL 86-014WP, Cambridge, MA: Energy Laboratory, Massachusetts Institute of Technology, 1986.

Lade, G.E., C.-Y.C. Lin Lawell, and A. Smith. "Policy Shocks and Market-Based Regulations: Evidence from the Renewable Fuel Standard.” Working paper, Davis: University of California, Davis, May 2016. Internet site: http://www.des. ucdavis.edu/faculty/Lin/RFS_policy_shocks_paper.pdf (Accessed Septmber 28, 2015).

Lin, C.-Y.C., and F. Yi. "Ethanol Plant Investment in Canada: A Structural Model.” Working paper, Davis: University of California, Davis, n.d. Internet site: http://www.des. ucdavis.edu/faculty/Lin/Canada_ethanol_paper.pdf (Accessed November 2, 2015).

Linton, J.A., J.C. Miller, R.D. Little, D.R. Petrolia, and K.H. Coble. "Economic Feasibility of Producing Sweet Sorghum as an Ethanol Feedstock in the Southeastern United States." Biomass and Bioenergy 35,7(2011):3050-57.

Majd, S., and R.S. Pindyck. "Time to Build, Option Value, and Investment Decisions.” Journal of Financial Economics 18,1(1987):7-27.

Maung, T.A., and C.R. Gustafson. "The Economic Feasibility of Sugar Beet Biofuel Production in Centeral North Dakota." Biomass and Bioenergy 35,9(2011):3737-47.

McDonald, R.L., and D.R. Siegel. "Investment and the Valuation of Firms When There Is an Option to Shut Down." International Economic Review 26,2(1985):33149.

McGrath, J.M., and B.J. Townsend. "Sugar Beet, Energy Beet, and Industrial Beet.” Industrial Crops: Breeding for BioEnergy and Bioproducts. V.M.V. Cruz and D.A. Dierig, eds. New York: Springer, 2015, pp. 81-99.

Nebraska Energy Office. "Ethanol Average Rack Price, F.O.B. Omaha, Nebraska.” Internet site: http://www.neo.ne.gov/statshtml/66.html (Accessed November 20, 2015). 
Outlaw, J.L., L.A. Ribera, J.W. Richardson, J. da Silva, H. Bryant, and S.L. Klose. "Economics of Sugar-Based Ethanol Production and Related Policy Issues." Journal of Agricultural and Applied Economics 39,2(2007):357-63.

Paulson, N.D., B.A. Babcock, C.E. Hart, and D.J. Hayes. 2008. "An Insurance Approach to Risk Management in the Ethanol Industry." Agricultural and Resource Economics Review 37,1(2008):51-62.

Pederson, G., and T. Zou. "Using Real Options to Evaluate Ethanol Plant Expansion Decisions.” Agricultural Finance Review 69,1(2009):23-35.

Pindyck, R.S. 1991. "Irreversibilty, Uncertainity, and Investment." Journal of Economic Literature 29,3(1991):1110-48.

Postali, F.A.S., and P. Pichcetti. "Geometric Brownian Motion and Structural Breaks in Oil Prices: A Quantitative Analysis.” Energy Economics 28,4(2006):506-22.

Rahmani, M., and A. Hodges. Potential Feedstock Sources for Ethanol Production in Florida. Institute of Food and Agricultural Science (IFAS) Extension Service, University of Florida, FE650, July 2006. Internet site: http://edis.ifas.ufl.edu/pdffiles/FE/FE65000.pdf (Accessed Septmber 30, 2014).

Renewable Fuel Association. "Industry Statistics." Internet site: http://www.ethanolrfa. org/pages/statistics (Accessed January 2015).

Schmit, T.M., J. Luo, and J.M. Conrad. "Estimating the Influence of Ethanol Policy on Plant Investment Decisions: A Real Options Analysis with Two Stochastic Variables.” Energy Economics 33,6(2011):1194-205.

Schmit, T.M., J. Luo, and L.W. Tauer. "Ethanol Plant Investment Using Net Present Value and Real Options Analyses.” Biomass and Bioenergy 33,10(2009):144251.

Shapouri, H., M. Salassi, and J. Fairbanks. The Economics Feasibility of Ethanol Production from Sugar in the United States. U.S. Department of Agriculture, July 2006. Internet site: http://www.usda.gov/oce/reports/energy/EthanolSugarFeasibilityReport3.pdf (Accessed September 30, 2014).

Thome, K.E., and C.-Y.C. Lin Lawell. "Investment in Corn-Ethanol Plants in the Midwestern United States: An Analysis Using Reduced-Form and Structural Models.” Working paper, Davis: University of California, Davis, October 9, 2015. Internet site: http://www.des.ucdavis.edu/faculty/Lin/ethanol_US_paper.pdf (Accessed November 12, 2015).

Trigeorgis, L. Real Options: Managerial Flexibility and Strategy in Resource Allocation. Cambridge, MA: MIT Press, 1996.

U.S. Department of Agriculture (USDA). "Feed Grains Database.” USDA, Economic Research Service, 2016. Internet site: http://www.ers.usda.gov/data-products/feed-grainsdatabase.aspx (Accessed August 29, 2016).

U.S. Department of Labor (USDL). "Consumer Price Index: All Urban Consumers (Series CUUR0000SA0).” USDL, Bureau of Labor Statistics, 2010. Internet site: http://www.bls.gov/cpi/ (Accessed August 12, 2015).

Wamisho, K., D. Ripplinger, and A. De Laporte. "Costs of Joint Production of Ethanol and Industrial Sugar Juice Using Energy Beets in the Northern Plains of the United States.” Biofuels, Bioproducts, and Biorefining 9,6(2015):749-59.

Wetzstein, M.E. "Should We Invest in Biofuels?" Journal of Agricultural and Applied Economics 42,3(2010):395-401.

Wisner, R. "Ethanol Economic Crisis: Potential Impact on Corn Use \& Ethanol Production vs. Mandated Ethanol Use.” AgMRC Renewable Energy Newsletter, February 2009. 
Internet site: http://www.agmrc.org/renewable_energy/ethanol/ethanol-economic-crisispotential-impact-on-corn-use-and-ethanol-production-vs-mandated-ethanol-use/ (Accessed November 17, 2014).

Yi, F., C.-Y.C. Lin, and K. Thome. "An Analysis of the Effects of Government Subsidies and the Renewable Fuels Standard on the Fuel Ethanol Industry: A Structural Econometric Model.” Working paper, Davis: University of California, Davis, n.d. Internet site: http://www.des.ucdavis.edu/faculty/Lin/ethanol_subsidy_paper.pdf(Accessed November 12, 2015).

Yi, F., and C.-Y.C. Lin Lawell. "What Factors Affect the Decision to Invest in a Fuel Ethanol Plant? A Structural Model of the Ethanol Investment Timing Game." Working paper, Davis: University of California, Davis, August 2016. Internet site: http://www.des.ucdavis.edu/faculty/Lin/Europe_ethanol_paper.pdf (Accessed August 29, 2016). 